\title{
Interculturalidad y educación
}

Tomás Calvo Buezas

Catedrático de Antropología Social, UCM

Director del Centro de Estudios sobre Migraciones y Racismo (CEMIRA)

\section{Melilla, un laboratorio privilegiado de multiculturalidad enriquecedora}

El mundo del futuro será cada vez más un mosaico pluricultural multiétnico, coincidiendo culturas, religiones, pueblos y lenguas diversas dentro de un mismo espacio físico. Aprender a convivir en la diferencia, respetando otras formas de vida y aprendiendo mutuamente de ellas, es el desafío del futuro, particularmente educativo.

Melilla, por su multiculturalidad de cristianos, musulmanes y judios, y otras culturas, es un laboratorio privilegiado de cómo debe conseguirse la unidad en la pluralidad, debiendo incrementarse cada vez más, particularmente por el sistema educativo, la convivencia respetuosa, e incluso el enriquecimiento mutuo y el mestizaje de dos grandes culturas y civilizaciones, como son la cristiana y la civilización musulmana.

El desafío del siglo XXI, a nivel mundial, es el diálogo entre el Islam y el Cristianismo. $Y$ dentro de España, Melilla y Ceuta deberían ser unos modélicos ejemplos de convivencia multicultural y multireligiosa, siendo crucial el papel que debe jugar en este complejo y difícil proceso, la educación intercultural a todos los niveles.

\section{Globalización y mundo injusto}

Nunca como ahora formamos parte toda la humanidad de una aldea global, interrelacionada por los medios de comunicación y caracterizada por la integración, el universalismo y la globalización. El mundo se ha convertido en una plaza grande, en un ágora, donde se mueven gentes de todas las razas y culturas, y en un gran mercado 
en el que libremente transitan capital, tecnología, recursos, empresas y productos. Algunos analistas explican el incremento de esta "integración universalista", entre otros factores, por el triunfo del capitalismo liberal, de naturaleza transnacional y expansionista; ello explicaría la ruptura de fronteras étnicas y culturales cerradas. Con la caída de los Estados Comunistas, el imperante capitalismo habría desarrollado aún más su dimensión universalista, integradora y globalizadora. Ahora bien, esta expansión capitalista mundial produce dialécticamente otros efectos, como son la desintegración social, las fanáticas resistencias nacionalistas y los baluartes étnicos particularistas. ¿Por qué estos procesos contrarios a la globalización universalista? Porque el capitalismo, a la vez que integra la producción y el mercado, conlleva el incremento de la competencia entre los diversos sectores sociales y entre los diversos países, distancia aún más el Norte/Sur y jerarquiza aún más la estructura desigual del poder económico en manos de la docena de países ricos del Primer Mundo. Este proceso debilita la soberania nacional y las lealtades de etnia y religión, por lo que a veces estas fuerzas sociales explotan en un exagerado fanatismo étnico, nacionalista o religioso. En este sentido algunos autores hablan de cómo en nuestra sociedad moderna de consumo se opera a la vez un proceso "universalista" de cierta homogeneidad económica, cultural y social, que podría metafóricamente denominarse de destribalización a nivel estructural; y a la vez se produce dialécticamente, como en un espejo cóncavo, un proceso inverso "particularista", etnocéntrico y nacionalista de retribalización a nivel simbólico de identidad étnica.

En saber armonizar esa dimensión universalista abierta y esa conveniente lealtad étnica y patria, consiste el desafio del futuro. Si el equilibrio se rompe, suele hacerse por el punto más flojo y débil, que es la "abstracta" dimensión universalista. Parece ser que en caso de conflictos de lealtades y competencias de recursos, se incrementa el particularismo étnico-nacional con el rechazo del "otro y del diferente", recrudeciéndose los prejuicios y la búsqueda de chivos expiatorios; y por eso mismo, son en esas crisis sociales donde hay que mantener la cabeza clara y el corazón abierto.

La llamada globalización es un proceso complejo y ambivalente. Por una parte, a nivel productivo, tiende a conectar, a una escala mayor que la lograda en siglos pasados, las capacidades productivas y creativas de las personas y la infinidad de recursos y medios tecnológicos utilizados para satisfacer las necesidades humanas con los circuitos de la economía mundial. Según el Programa de la Naciones Unidas para el Desarrollo CONU 1.997) la globalización puede definirse como "la ampliación y profundización de las corrientes internacionales de comercio, finanzas e información en un solo mercado mundial integrado. La receta consiste en liberalizar los mercados nacionales y mundiales en la creencia de que las corrientes libres de comercio, finanzas e información producirán el mejor resultado para el crecimiento del bienestar humano. Todo se presenta con un aire de inevitabilidad y convicción abrumadora. Desde al auge del libre comercio en el siglo XIX no había una teoría económica que concitara una certidumbre tan generalizada". 
De ahí las justas críticas a la globalización como fenómeno inexorable, y sus implicaciones, rechazando tanto la dictadura del mercado, como del pensamiento único con la consecuente homogeneización cultural, y apostando por la biodiversidad cultural y el pensamiento crítico y humanizador. Como certeramente advertía Susan George, Directora del Transnational Institute de Amsterdan: "Solo ahora y quizás durante la revolución industrial en Gran Bretaña hemos legitimado el mercado para decidir sobre nuestras vidas. Y si los dejamos solos, no sólo destrozarán la tierra, sino que sus sistemas sólo permitirán que subsista el $5 \%$ más rico del mundo. Como ellos dicen, coge lo mejor y tira el resto a la basura". (EI País, 27-I-2000).

$Y$ hoy la "basura" económica del mundo, si comparamos Norte/Sur, lo constituyen millones de seres humanos, que en pleno siglo XXI en el tercer milenio, pasan hambre y sufren por no satisfacer necesidades mínimas. Unos datos nos pintarán mejor el cuadro. "Las 225 personas más ricas del mundo poseen tanto como un $47 \%$ de la humanidad. La ONU cumple cada año la ingrata tarea de decirles al mundo cuál es la situación de los habitantes del planeta. Y el extenso informe de 1998, que no pretende ser "apocalíptico", confirma el proceso de concentración de la riqueza. Los 225 personajes más ricos acumulan una riqueza equivalente a la que tienen los 2.500 millones de habitantes más pobres (el $47 \%$ de la población). Las desigualdades alcanzan niveles de escalofrio: las tres personas más ricas del mundo (Bill Gates, el Sultán de Brunei y Warren E. Buffett) tienen activos que superan el PIB (Producto Interior Bruto) combinado de los 48 países menos adelantados (600 millones de habitantes). $Y$ dicho de otra forma: El $20 \%$ de la población controla el $86 \%$ de la riqueza mundial. 1.300 millones de pobres viven con ingresos inferiores a un dólar diario; los bienes de 358 personas más ricas de la Tierra son más valiosas que la renta anual de 2.600 millones de habitantes (1). Con tanta riqueza en algunos países y tantísima pobreza en otros muchos ćcómo sorprenderse de las migraciones y del peregrinaje al paraíso prometido del Norte, que tan fantásticamente pintan en el Tercer Mundo las televisiones policromas modernas, que son el pan y el opio del pueblo para tantos millones de pobres en el mundo? Y ahora contrastaremos ese mundo injustamente repartido, que a su vez es desproporcionado demográficamente: los países industriales ricos son "pobres" demográficamente, mientras que los países pobres económica e industrialmente son "ricos" en población. He aqui unas previsiones de futuro, aunque hay que tomar los datos con cierta cautela.

El año 2000 amaneció en sus primeros días de Enero, con la publicación de un Informe de las Naciones Unidas sobre las expectativas demográficas del siglo XXI en Europa, poniendo de manifiesto la baja natalidad y la necesidad de importar inmigrantes. Los titulares, en la primera página, de los grandes periódicos no pueden ser más llamativos y elocuentes: “Europa necesita 159 millones de inmigrantes hasta el año 2025. Los técnicos conminan a la UE a paliar el envejecimiento de su 
población". (El País, 7-1-2000). Estas previsiones están hechas, teniendo en cuenta las actuales tasas de natalidad, ante lo cual hay que tener ciertas reservas, pues en tan largo tiempo (25-50 años) es muy posible que cambien las tasas de natalidad como está sucediendo en algunas países desarrollados del norte de Europa. Según las fuentes del Informe de la ONU, España con la tasa de fecundidad más baja del mundo $[1,07$ hijos por mujer en edad fértil), tendría 30.226 .000 habitantes en el año 2050, menos que los actuales 39.628.000. Según la División de población de las Naciones Unidas (El País, 28 de Febrero 2001), las previsiones de población para el año 2050 en millones de habitantes, comparando la población actual (2000) y la previsible en el 2050 por zonas geográficas sería la siguiente: Europa (actual 727) previsto para el 2050, 603 (- 124); América del Norte (actual 314), prevista para el 2050, $438(+124)$; Sudamérica (actual 519), previsto para el 2016, 806 (+ 287); África (actual 794), prevista para el 2050, 2.000 (+ 1.206); Asia (actual 3.672), prevista para el 2050, $5.428(+1.750)$. Las diferencias entre el Primer Mundo desarrollado y el Tercer Mundo son evidentes, aunque estas previsiones están expuestas a muchas variaciones en tan largo espacio. Para España las variaciones de población son del 39.600 .000 en el 2000 a los 36.600 .000 en el año 2025 y 30.200 .000 en el año 2050. Para España, según estas previsiones, se necesitarían 12 millones de inmigrantes hasta el año 2025. Las variaciones de población entre Europa y su vecina África son notables: después de la Segunda Guerra Mundial Europa representaba el $22 \%$ de la población del mundo y África solo el $8 \%$. Ahora las dos zonas tienen la misma proporción del 13\%. Sin embargo para el año 2050 , África estará tres veces más poblada que Europa. $Y$ con referencia a España, este dato es significativo. Hace 50 años, España tenía tres veces más población que Marruecos, mientras que dentro de medio siglo. Marruecos tendrá un $60 \%$ más de habitantes que España. Por otra parte, la media de edad y el envejecimiento de la población es muchísimo mayor en los países ricos, que en los pobres, siendo España uno de los futuros países del mundo con una mayor media de vida. En el último censo, la población de la Unión Europea subió a 377,6, millones, creciendo un 1.150 .000 personas, de las cuales el $70 \%$ de este crecimiento se debió a la llegada a la UE de 816.000 inmigrantes.

Por todo ello la Unión Europea ha reconocido que su política de "inmigración 0" fue un error, y así la Unión Europea ha abordado un plan de inmigración ante el envejecimiento de Europa. De otro lado la Comisión Europea hace hincapié en que el previsto envejecimiento de la población europea hace necesario un flujo de entrada de inmigrantes en la UE. "Aunque la inmigración no será una solución en sí misma a los problemas del mercado laboral" señala un informe, "los inmigrantes pueden suponer una aportación positiva a ese mercado laboral, al crecimiento económico y al mantenimiento de los sistemas de protección social". Pero la Comisión Europea también defiende que Europa desarrolle una política conjunta para que los inmigrantes se incorporen de pleno derecho a los países que les acojan y para ello propone "una especie de contrato" entre ambas partes. Según ese contrato "las sociedades deberán aceptar las 
diferencias, que también son fuente de riqueza cultural", pero también "los inmigrantes deberán respetar los valores comunes propios de la sociedad europea, como el resto de los derechos humanos, las reglas del sistema democrático, la igualdad entre hombres y mujeres, el pluralismo....".

\section{Racismo y terrorismo: las dos lacras de las sociedades modernas}

En la sociedad española parecen entrecruzarse en los últimos años dos coordenadas, aparentemente contradictorias, que explosionan a la vez, o sucesivamente, en hechos y discursos, saltando a las primeras páginas de los periódicos y a la TV, a la vez que nos conmocionan y despiertan de nuestra rutina. La coordenada repelente y sucia la componen los crímenes terroristas, la agresión a los otros diferentes, el sucio racismo y xenofobia que pueden llegar hasta el asesinato de una inmigrante dominicana, por el solo delito de ser pobre, negra y extranjera, o participar grupalmente en la "caza del moro". Pero a la par, inmediatamente después de estos crimenes terroristas, asesinatos racistas o agresiones xenófobas surgen -como un gigante dormido - todo un pueblo unido y compacto, de las más diversas ideologías y estratos sociales, que en miles de rituales comunitarios de rebelión, gritan, exigen y claman por una España pacífica, solidaria y tolerante. Las manifestaciones que tuvieron lugar en contra de los asesinatos de ETA, la más fascista y perversa versión del racismo neonazi hoy en España, han constituido una muestra modélica de ese grito dramático por la paz y por la convivencia plural, respetando las diferencias. $Y$ de igual modo la firme y contundente posición de todos los medios de comunicación y de todos los sectores sociales en contra de los actos xenófobos ocurridos en El Ejido es una buena muestra de ellos. La Europa del siglo XXI será cada vez más un mosaico ultiracial y pluricultural, una Europa fecundada con emigrantes y etnias del Tercer Mundo, como modos de vida muy diferenciados de la cultura occidental. Si los jóvenes de ahora - protagonistas europeos el mañana - no aprenden a convivir juntos en la diferencia, es previsible sociológicamente el auge del racismo y de la xenofobia, recrudeciéndose aún más los conflictos interétnicos. También España camina por ese camino de la multiculturalidad y el pluralismo étnico-racial. La sociedad española ha dejado de ser una sociedad tradicional, homogénea étnica y culturalmente a nivel de valores y creencias, con una identidad única y un único sistema axiológico. De ahí la necesidad de educar a todos los jóvenes de los diversos sistemas éticos y culturales en los valores democráticos de la solidaridad y respeto a las minorías, a los "diferentes", a los "otros"; de lo contrario podemos caer en el peligro de estar "criando cuervos" con tintes xenófobos y racistas.

$Y$ a nivel internacional, en Septiembre del 2001, un hecho aterrorizó al mundo entero. El choque frontal del 11-S-01, con el derrumbe de torres superpotentes y la muerte de 3.000 inocentes en el corazón del imperio mundial, infligido por grupos de fanáticos suicidas, que tienen detrás una poderosa máquina de terror sustentando en ide- 
ologías y creencias integristas, fundamentalistas y violentas, ha constituido también un choque frontal de nuestros esquemas mentales, de nuestras buenas y malas intenciones y acciones, de nuestras estrategias y planes de futuro en el pensar y quehacer en todos los campos, incluyendo el nuestro de universitarios formadores en opiniones, ideologías y sistemas de valores.

No es el momento ni el lugar para analizar tan complejo y trascendente proceso de terrorismo-guerra, que estamos viviendo y sufriendo. Solamente enfatizar muy esquemáticamente su relación con lo que hemos venido apuntando en la anterior introducción. Entre las múltiples y necesarias medidas que deben tomarse para acabar con el terrorismo, con el fundamentalismo religioso violento y con las causas del malestar de los países árabes, está la educación en los valores de la justicia, de la igualdad humana, de la solidaridad, de la democracia, de la tolerancia y del respeto a otras religiones y culturas. $Y$ esta necesidad de educación en valores pacíficos y democráticos es tan necesaria en Occidente como en Oriente, entre cristianos y musulmanes, entre creyentes y agnósticos. El problema no está en que existan civilizaciones diversas, ni religiones diferentes, ni culturas diversas, cuya pluralidad es un bien para toda la humanidad. El mal no está en el Islam, ni en el Judaísmo, ni en el Cristianismo. El mal está en la perversión idolátrica y asesina de una religión legítima (la que sea), pero que la pervertimos, la pudrimos, la transformamos sustantivamente en un ídolo, que convierte a los diferentes en enemigos que hay que exterminar. Lo perverso de Bin Laden es asesinar, sirviéndose de una religión en sí pacífica, pero que él pervierte para ideologizar y legitimar su fanatismo violento fundamentalista y sus sueños monstruosos de terror. Ésa no es la religión de la inmensa mayoría de los 1.200 millones de musulmanes en el mundo, que tiene su rostro pacífico y enseña a no matar. Con ese tipo de interpretación perversa del Islam no se identifica la inmensa mayoría de sus líderes religiosos árabes y creyentes, que han condenado en forma enérgica el terrorismo del 11-S-01.

Los cristianos sabemos también bastante de eso, y tenemos que reconocer nuestras culpas. Cuando matamos en "guerras santas" a los diferentes, aunque dijeran hacerlo en nombre de Dios, era una perversión de la religión predicada por en sus Bienaventuranzas y en su Mandamiento Nuevo de Amor al Prójimo.

\section{Nacionalismos, fundamentalismos religiosos y terrorismos en un mundo globalizado}

Cuando los medios de comunicación nos despiertan a la bruta realidad de crímenes terroristas, sea el asesinato de la dominicana Lucrecia Pérez, los crímenes de ETA, los ataques racistas en El Ejido y el ataque terrorista del 11 de Septiembre del 2001 (11-09-01), siempre nos quedamos perplejos y sorprendidos por tan crueles comportamientos, que creíamos fatuamente ausentes de nuestras sociedades civilizadas modernas. Por su macabra y apocaliptica visión y por sus gravisimas consecuencias, hagamos referencia al ataque contra Estados Unidos, reflexionando, a nivel personal, 
sobre las implicaciones que la diversidad de religiones, culturas y niveles económicos pudieran tener en esos fenómenos y en la convivencia de un mundo en paz.

Ante tales atrocidades, y ante los terrorismos nacionalistas o integrismos violentos religiosos, algunos pensadores contemporáneos sugieren que hay que abandonar en el presente milenio toda identidad pública nacionalista o religiosa (países musulmanes), como origen y fundamento legal de derechos públicos, debiendo ser sustituida por la identidad pública de "ciudadano del mundo", extensible a toda persona, con derechos y deberes basados en los derechos humanos universales. Según esta opinión, la identidad patria, religiosa o étnica es obsoleta y perniciosa. Obsoleta, porque cada vez más las "naciones", como entidad pública, tienen menos vigencia; se trata de una identificación pública histórica, que tuvo su legislación y función en la edad moderna, pero que es transitoria y por lo tanto cambiable; antes la identidad pública, fuente legal de derechos, era ser "siervo del tal señor feudal", y luego ser "vasallo de tal rey", posteriormente ser "ciudadano de una nación-estado"; y en el futuro será "la ciudadanía universal humana". Argumentan, además, estos pensadores que estructuralmente todo nacionalismo encierra las simientes de la exaltación del propio grupo, la exclusión prejuiciosa de los otros, lo cual es el camino preparatorio para la discriminación, la intolerancia, la xenofobia y el racismo, bases para la posterior limpieza étnica, terrorismo político, violencia integrista religiosa, pudiendo llegar hasta el holocausto y los hornos crematorios. Por todo lo cual, concluyen estos intelectuales que la identidad pública legal nacionalista es una pertenencia rancia de campanario tribal, y además muy perniciosa socialmente por sus peligros de intolerancia, exclusión de los otros, xenofobia y racismo.

¿Qué decir de esta argumentación? En mi opinión, aunque contiene algunos puntos significativos de reflexión, concluye demasiado. Las identidades geográficas, ideológicas, étnicas, religiosas, en mi particular evaluación, son positivas, humanizadoras y funcionales: "no se puede ser ciudadano del mundo, si no somos y nos sentimos ciudadanos de alguna parte". Por ello las identidades deben ser círculos abiertos, que no excluyan el sentirnos identificados e integrados a otro nivel con otros grupos. Entonces, ¿̇dónde ésta el peligro del nacionalismo perverso xenófobo y del integrismo religioso violento? Cuando convertimos nuestra lealtad nacional o religiosa en un fetiche idolátrico, al que servimos como a un dios, y "adoramos" en exclusividad sobre todas las cosas, entregándole nuestra alma, nuestra vida y nuestro corazón. Pero esto es una farsa, una perversión, una burla del sano amor patrio o religioso; es más, es substantivamente lo opuesto. Sirva una analogía. Una carne o un marisco podrido apesta, huele mal, es nefasto e indigesto, ceso quiere decir que por el peligro que tiene todo pescado de pudrirse, debemos dejar de comer para siempre marisco y considerarlo algo substantivamente pernicioso? Ya sabemos corruptio optimi pessima; cuanto mejores son las cosas, más nefastas son si se pudren; y esto sucede con la religión y el nacionalismo. Por eso, en mi opinión, los pensadores-inquisidores a toda lealtad patria/religiosa, como algo substantivamente perverso, concluyen demasiado. 
Es difícil, a veces, mantener esas lealtades con corazón abierto, facilitando -en vez de cerrarnos- la apertura humanitaria y solidaria a otras identidades nacionales, étnicas, religiosas, culturales, pero es posible conciliar lealtad patria y religiosa con ciudadanía universal y ecumenismo humanitario y tolerante.

\section{El multiculturalismo ¿̇gangrena de la sociedad?, ¿existen culturas con quienes no se puede convivir?}

El tema del multiculturalismo ha saltado a la opinión pública en España, en el último año, particularmente en dos ocasiones. En abril del 2001, con motivo de la presencia entre nosotros del reconocido pensador italiano Giovanni Sartori, presentado como el "príncipe de la ciencia política de la izquierda liberal de Europa", se suscitó un debate y una cierta conmoción en la opinión pública, que ha podido servir en algunos sectores como armazón ideológico para atrincherarse en posiciones y actitudes reaccionarias, cuando no xenófobas, precisamente por venir de un reconocido y combatido intelectual de izquierdas.

La segunda ocasión en que se ha presentado el debate público ha sido en los primeros meses del 2002 con motivo de las declaraciones del antropólogo Mikel Azurmendi, Presidente del Foro de la Inmigración, presentando el multiculturalismo como "grangena de la sociedad" democrática. Entre esos dos debates, habria que situar a nivel mundial el pavor ante el macro-terrorismo cometido por los fundamentalistas agresivos islámicos de Bin Laden, y la anterior ideología propagada por el norteamericano Samuel Huntington en su conocido libro Choque de civilizaciones (1997), enfatizando que los conflictos del futuro serán principalmente entre Occidente cristiano y Oriente islámico. Los musulmanes visualizan el proceso de modernización globalizadora, según Huntington, como un imperialismo de Occidente, que intenta imponer al mundo una cultura materialista, individualista, inmoral e irreligiosa, contra el cual hay que defenderse. A nivel nacional, habría que añadir, en el debate del multiculturalismo, el incidente público ante la permisividad o no, de poder llevar el pañuelo las alumnas musulmanas en los Colegios. Demasiadas cuestiones, de muy distinto calibre e importancia ética y política, con distintos niveles de discusión ideológica y académica que han producido -en mi opinión- más confusión que claridad en el necesario diálogo intercultural entre religiones y civilizaciones diferentes. Intentemos exponer, en primer lugar, el debate sobre el pensamientos y libro de Giovanni Sartori, ya que la posición de Mikel Azurmendi es fundamentalmente una repetición "a la española" de las mismas perspectivas teóricas-ideológicas.

El pensamiento y el libro La sociedad multicultural de G. Sartori (Taurus, 2001), es mucho más complejo y refinado, pero los titulares de los periódicos y propaganda del libro, así como sus expresiones vivaces y valientes, huyendo de lo políticamente correcto, pueden incitar -tal vez sin desearlo el autor- a interpretaciones que fomenten el nuevo fantasma europeo, que ha sustituido al "coco" del comunismo, por 
la amenaza de la islamofobia, que reduce e identifica a la inmigración magrebí con la religión islámica, reduciendo injustamente la religión del Dios Bueno y Misericordioso Alá, a la perversión minoritaria del fanatismo integrista de los talibanes violentos. He aqui algunos titulares de una entrevista de Hermann Tertsch con Giovanni Sartori en El Pais (8-IV-2001): "La inmigración sin límite es una amenaza" ... "la llegada incontrolada de inmigrantes que no quieren integrarse supone un riesgo para el pluralismo y la democracia" ... "El multiculturalismo en sí es una ideología perniciosa, porque fragmenta, divide y enfrenta" ... "Mucho político debería tener más en cuenta la ética de la responsabilidad frente a la fácil ética de los principios". $Y$ dentro de la entrevista tiene afirmaciones tan radicales y taxativas, como las siguientes: "En cuanto al argumento de que la civilización actual y el Islam actual son fundamentalmente incompatibles, creo que es cierto y estoy dispuesto a defenderIo", añadiendo "el Islam que pasa ahora por un fuerte renacimiento, es, yo diria hoy que absolutamente, al cien por cien, incompatible con la sociedad pluralista y abierta en Occidente.... Los principios de las dos culturas son antagónicas y son ellos los que nos consideran a nosotros los infieles, aunque estén aquí (en Europa), no nosotros a ellos". Según Giovanni Sartori, hay tres criterios para establecer la supervivencia en la diversidad. El primero es "la negación del dogmatismo, precisamente todo lo contrario de lo que predica el Islam". El segundo es "que ninguna sociedad puede dejar de imponer el principio de impedir el daño y esto supone que todas nuestras libertades siempre acaban donde supondría un daño o peligro del daño al prójimo". $Y$ el tercero y quizás más importante es el de la reciprocidad. La reciprocidad dentro de la doctrina de la tolerancia supone que no podemos ser tolerantes con la intolerancia. Yo soy tolerante como anfitrión, pero tú tienes que serlo asimismo desde tu papel de huésped. La religión católica ha sido mucho tiempo intolerante, hoy no se lo puede permitir... Pero el Islam sigue pensando en el poder de la espada".

En otra declaración suya (E/ País, 6-IV-2001), relaciona esta incompatibilidad del Islam con el tema de los inmigrantes musulmanes en Europa: "La distancia cultural es un elemento fundamental para calibrar la inmigración. $Y$ el Islam representa el extremo más alejado de Europa por su visión teocrática del mundo. Sus creencias están en contra del sistema pluralista".

En su libro La sociedad multiétnica: pluralismo, multiculturalismo y extranjeros (2001) trata fundamentalmente de la crisis del melting pot americano y la crítica al multiculturalismo académico de los Estados Unidos y a la política del affirmative action, que refuerzan la tendencia a fabricar la diversidad y a crear guetos cerrados e impiden a las minorías étnicas atravesar las fronteras interculturales. De ese "peligro" y desintegración multicultural, intenta preveer G. Sartori a la sociedad europea, que es distinta a la americana, con una cultura occidental firme, que no debe ser amenazada pro una inmigración incontrolada y la concesión de derechos de ciudadanía a extranjeros de difícil o imposible integración, como los musulmanes. El autor aboga por una sociedad plural, pro no multicultural, porque "el multiculturalismo no persigue una integración diferenciada, sino una desintegración multiétnica”, según 
se dice en la contraportada del libro: "A partir de esta premisa el libro se pregunta hasta qué punto la sociedad pluralista puede acoger sin disolverse a "enemigos culturales" que la rechazan. Porque todos los inmigrantes no son iguales. $Y$ porque el inmigrante de cultura teocrática plantea problemas muy distintos del inmigrantes que acepta la separación entre religión y política. El análisis teórico sirve aquí para encuadrar los problemas prácticos que comentaristas y políticos están afrontando con inconsciente ligereza. $Y$ es que Sartori no se deja hechizar por los lugares comunes de lo "políticamente correcto". Y la propaganda de la faja de papel que rodea el libro tiene estas frases provocadoras y ganchos publicitarios: "No todos los inmigrantes son iguales ¿Debe la sociedad pluralista ser tolerante con sus "enemigos culturales?".

El debate en torno al libro y a las declaraciones del autor saltaron a la opinión pública. El mismo periódico de El País (6-V-2001), que le ha servido de tribuna cualificada y generosa de publicidad, dedicó una página de OPINIÓN, titulado "¿iHay una inmigración imposible de integrar?". Al debate fueron invitados dos especialistas: el profesor Joaquín Arango y el eurodiputado Francés Samir Naïr. Bajo el título "Trato igual", J. Arango cuestiona la imposibilidad de que se integren algunos inmigrantes, según se desprende el libro de Sartori, cuando "pertenece a una cultura fideista o teocrática" y que "las diferencias étnicas producen "extrañezas insuperables". Estas afirmaciones de Sartori, dice certeramente Joaquín Arango, han producido "un debate estéril, mal planteado y, para sociedades como la española o la italiana, en una fase incipiente del proceso que las va a convertir en pluriétnicas y multiculturales, extemporáneo; un caso de acento mal situado", según J. Arango. $Y$ añade: "No parece que el debate, tal como se ha planteado, conduzca a parte alguna. Pero, además, el juicio de hecho sobre el que reposa es harto cuestionable: cualesquiera que sean las dificultades que obstaculizan la integración de las minorías étnicas, no parece que el diagnóstico de inintegrabilidad describa adecuadamente la realidad de los paquistaníes en el Reino Unido, los turcos en Alemania u Holanda o los magrebíes en Francia o Bélgica".

Sami Naïr es muchísimo más contundente y duro con estos peligrosos planteamientos, y sin hacer referencia explícita a G. Sartori, escribe en su artículo titulado "No a otra limpieza de sangre".

"Después de la guerra se decla de los inmigrantes españoles en Francia. Bélgica, Alemania y Suiza que no se podían integrar en la sociedad moderna europea: "demasiados ruidosos", "demasiado violentos". "Entre los años sesenta y ochenta volvimos otra vez con la misma... con respecto a los inmigrantes magrebies en Francia y en Bélgica. Los indios y los paquistaníes no estaban mejor parados en Inglaterra. Hoy día se escupe el mismo veneno en España. $Y$ es que siempre se es "imposible de asimilarse" para alguien. Pero hay, sin embargo, una diferencia cualitativa: nunca ningún Gobierno europeo, al menos desde la II Guerra Mundial, ha osado sostener este discurso oficialmente. Ahora bien, la insistencia actual de algunos responsables gubernamentales españo- 
les sobre la "diferencia cultural" de los musulmanes y, en cambio, su apología de la proximidad cultural de los suramericanos es extremadamente inquietante. Corresponde a una política de visados discriminatoria y de tratamiento social particular que tiene algo de racismo de Estado. Sin embargo, los inmigrantes musulmanes han demostrado en toda Europa una capacidad de adaptación excepcional, sus hijos se integran rápidamente y su contribución a la cultura europea ya es reconocida por todos. El caso de Francia lo demuestra ampliamente. Los cristianos franceses, que expresaron tan a menudo una gran solidaridad con los inmigrantes musulmanes, to han comprendido bien. $\mathrm{El}$ debate actual en España sobre este falso problema es indigno. Indigno de España. que da la impresión, después de los acontecimientos de El Ejido, de no haber liquidado su pasado racista, y dictatorial: indigno de elites políticas españolas que invocan todavia más "ruidosamente" un europeísmo de fachada, mientras cierran los ojos a la barbarie en aumento en el país; infamante, en fin, para los propios inmigrantes de confesión musulmana, ofrecidos como pasto a una opinión pública desorientada y a menudo influida por prejuicios malsanos".

"El aumento del flujo de inmigrantes llegados a España en los últimos años y el proceso de su integración social en el pais han despertado distintos debates -ya desarrollados en otros países europeos- sobre este fenómeno universal. Junto con la discusión sobre la situación legal de los inmigrantes, desencadenada por la reciente Ley de Extranjeria, hay otros aspectos del fenómeno que merecen una consideración serena y positiva. Entre ellos, el de si existe -como señalan algunas opiniones- una inmigración "imposible de integrar" en función de su religión o sus costumbres"

Y termina Sami Naiir con esta reflexión ética: "La España que nosotros amamos no puede ser ensuciada por los nuevos apologistas de la limpieza de sangre". Desde otra ladera ideológica-política, como es el ABC, el 11 de abril de 2001, en un magnífico artículo de fondo, bajo el título “¿Qué hacemos con los inmigrantes?", José María Martín Patino. Presidente de la Fundación Encuentro, se refería a este debate con estas reflexiones: "La versión castellana del ensayo de Giovanni Sartori Pluralismo, multiculturalismo e estranei, es decepcionante, al menos para los entusiastas como yo del viejo politólogo italiano. Es inevitable que me refiera a este escrito con la mayor brevedad posible. Ante un problema tan grave y complejo, no se puede describir la "sociedad pluralista" como una Arcadia feliz, ni la "multicultural" como un infierno. Ambas formas de sociedad están vivas en nuestra vieja Europa y $\sin$ fronteras definidas. Lo que tenemos que plantearnos es cómo convertir la sociedad "multicultural", esa mera yuxtaposición de etnias, culturas y religiones, en una sociedad pluralista. No existe ningún pueblo que esté libre del racismo y de la xenofobia. Invocar los riesgos del multiculturalismo, cómo hace Sartori, para poner fronteras a la inmigración, no deja de ser una simpleza".

En Europa -y España - se hace cada vez más urgente y necesario, a todos los niveles, el diálogo creciente entre el Cristianismo y el Islam, como hace años fuera fructifero para ambas laderas ideológicas el diálogo entre comunistas y cristianos. Este diálogo 
va más allá del ecumenismo religioso, y esta cimentado en factores demográficos, sociológicos, culturales y políticos: dos tercios de los inmigrantes residentes de la Unión Europea profesan la fe musulmana, una población que supera los 10 millones de personas; en algunos colegios de Berlín son más los niños turcos que alemanes y en Bruselas la mitad de los niños que nacen son hijos de magrebíes. En Birmingham [Inglaterra) el 10\% de la población es musulmana. En Francia algunos demógrafos han comparado la tasa de natalidad que se dan en las familias de cultura cristiana y las de familias islámicas, concluyendo que dentro de un cuarto de siglo los musulmanes representarán una cuarta parte de la población total.

Helmut Schmidt, ex-presidente de Alemania, en su reciente obra, La autoafirmación de Europa: Perspectivas para el siglo XXI (2002), nos hace ver la cercanía del Islam. 300 millones viven cerca de nosotros, desde Marruecos hasta Egipto, e incluso dentro de Europa se incrementará notablemente el número de ciudadanos europeos musulmanes, con la entrada en la Unión de Turquía y otros países del Este; de forma que a finales del siglo XXI habrá tantos turcos como alemanes y franceses juntos. Por todo eso, afirma Helmut Schmidt, "los europeos debemos respetar la identidad religiosa y cultural de nuestros vecinos islámicos, entre otras razones para conservar a largo plazo nuestra propia identidad europea".

Ante esas cifras y previsiones, algunos se asustan y temen una nueva versión de la invasión turca de la Europa cristiana. Si queremos construir una Europa democrática, todos los pueblos, culturas y religiones deben por igual de caber y participar, cumpliendo todas sus obligaciones constitucionales, con respeto a los Derechos Universales Humanos y a los valores democráticos de toda sociedad libre, pacífica e igualitaria.

Mikel Azurmendi, antropólogo vasco y Presidente del Foro para la Integración de los Inmigrantes, autor de "Estampas de El Ejido" (2002), ha hecho declaraciones públicas, incluidas las efectuadas ante el Senado, causando un cierto revuelo, terminando el debate en mayor confusión que en clarificación del fenómeno, y sirviendo -independientemente de las buenas intenciones del autor- de un reforzamiento de las posiciones xenófobas contra los inmigrantes, particularmente contra los marroquíes y musulmanes. En un artículo suyo ("El Pais". 23-II-2002), titulado Democracia y cultura, expresa opiniones como las siguientes:

\footnotetext{
"Se llama ahora multiculturalismo al hecho de que en el seno del mismo Estado de derecho coexistan una cultura democrática, por ejemplo la nuestra cultural, con otra u otras culturas no necesariamente democráticas. Es decir, cuando junto a nuestro actual tejido social de civismo laico, pero colocadas de manera aparte y sin interactuar con él, estuviesen cohabitando conductas masivas de personas sin igualdad jurídica que interactuasen entre sí mediante recursos simbólicos de desigualdad y jerarquía: no en virtud de imparcialidad y derecho, sino de supeditación discriminante entre varón y mujer. mayor y joven, rico y pobre, clérigo y sübdito fiel. U otra cualquiera. Pero, por suerte, en España no existe multiculturalidad todavía aunque si existen proyectos. mensajes o intenciones de crear
} 
multiculturalismo. Cuantos hablan de que los inmigrantes son etnias piensan -lo quieran o no- en algo multicultural, piensan en que grupos enteros de gente inmigrante se coloquen aparte, en ghettos o reservas y mantengan ahi su modo de vida colectivo de alli. Pero a España no nos llegan etnias. sino personas singulares con proyectos personales. Personas sueltas o con su familia que quieren mejorar su vida. $Y$ por muy parecidas que sean unas y otras y tengan origenes culturales similares, cada persona llega con su propio proyecto, a intentar realizarlo."

$Y$ termina con esta afirmación radical:

"El multiculturalismo es hoy una confusión teórica porque imagina que las relaciones son interétnicas, entre nosotros. los de la sociedad mayoritaria, y todos los demás, tomados en bloques étnicos minoritarios. Por eso como proyecto más a menos consolidado de relación interétnica en agrupamientos separados, unos al margen de otros, el multiculturalismo sería una gangrena fatal para la sociedad democrática" (2).

¿Qué podemos concluir de tanto debate sobre el multiculturalismo? Sin intentar "dogmatizar" sobre tal complejo, poliédrico, difuso y multiforme fenómeno, yo me atrevería a sugerir lo siguiente. El multiculturalismo tiene muchos significados, variadas manifestaciones, múltiples variaciones según tiempos, espacios y sociedades, por lo que no puede reducirse a una sola forma concreta, "maldiciéndola" como gangrena de la sociedad o "bendiciéndola" acriticamente como paraíso piadoso. El multiculturalismo, fundamentalmente, hace referencia a un fenómeno social, como es la convivencia en un mismo entorno geográfico-social, donde permanecen y viven juntos grupos de distintas culturas, lenguas, religiones, etc. Esa convivencia de varias culturas puede ser un desafío y oportunidad excepcional para enriquecerse mutuamente y constituir una sociedad culturalmente más rica y desarrollada; el avance de las civilizaciones ha sido casi siempre el resultado del mestizaje enriquecedor de distintos pueblos, culturas y etnias. Ese es el multiculturalismo, que queremos para España, los que hemos apostado por una Europa pluricultural, multirracial y mestiza. Obviamente que esto exige, de ambas partes, una educación recíproca en la tolerancia, en la hospitalidad y en la apertura pluralista, respetando los derechos humanos, los valores democráticos y las leyes constitucionales de cada país. Y este proceso de educación y dialogo intercultural e inter-religioso es largo, costoso y diffcil, pero posible.

2. Sobre esta cuestión, se han hecho declaraciones en contra, particularmente de los Partidos Pollticos de izquierda y de las organizaciones no gubernamentales. También debates en la prensa, como el ofrecido por El País (24-II-2002) bajo el tema "Multiculturalismo e Inmigración", en el que participaron el diplomático José María Ridao. con su artículo " El oscurantismo reverenciado", y el periodista Hermann Tertsch con "Corrección política insensata". También Josep Ramoneda publicó su columna en el mismo periódico sobre este tema bajo el título "Contra el multiculturalismo piadoso". Desde una ladera crítica a la posición de M. Azurmendi, pueden verse los artículos de Mariano Fernândez Enguita "La carga del hombre blanco" (EI Pais. 11-III-2002) y el ilumninador y sensato artículo de Joaquín Arango "De qué hablamos cuando hablamos de multiculturalismo" (EI País, 23-III-2002) 
Este dialogo debe intensificarse aun más entre Oriente y Occidente, el Islam y el Cristianismo, entre las sociedades de larga tradición democrática y las de incipiente apertura democrática, con concepciones y costumbres diferentes en las relaciones familiares, en la participación cívica, en las libertades públicas. Occidente, y pensemos en España, ha sido también una sociedad teocrática, sin separaciones de Iglesia y Estado, con sumisión jurídica y fáctica de la mujer al hombre, sin participación democrática, con violencia religiosa intolerante como la Inquisición, con etnocidios y destrucciones de religiones y culturas. $Y$ hoy hemos cambiado; las culturas no son bloques inamovibles, son procesos cambiantes. $Y$ de hecho existen múltiples formas de vivir el Islam y ser musulmanes; no debiendo identificar a todos con algunos grupos y prácticas deleznables e intolerables, que violan los derechos humanos, que deben ser salvaguardados a toda costa, condenando a sus transgresores. Pero es injusto y falso reducir a todos los pueblos árabes e islámicos a esos fenómenos condenables, como tampoco es justo reducir la cultura de Occidente y del Cristianismo a ciertas injusticias y crimenes de guerra, que se cometieron y se cometen dentro de sus fronteras geográficas-sociales.

En resumen el multiculturalismo es un bien enriquecedor para una sociedad, si recíprocamente saben dialogar interculturalmente, respetando unos valores y normas mínimas de convivencia, como son el respeto a los derechos humanos y a las leyes constitucionales. Ahora bien, en el caso de que existan grupos, sean de cultura-etnia distinta, o de la misma nación y etnia - caso banda armada y asesina de ETA - que imposibilitan la convivencia pacífica de una sociedad ["societas", compuesta por "socios"), entonces, en ese caso particular, podemos hablar del multiculturalismo como "gangrena de la sociedad". Pero eso es una versión perversa y puntual, específica y concreta, entre las variadas formas enriquecedoras del multiculturalismo. La reducción de todo multiculturalismo a este tipo perverso de multiculturalismo antidemocrático, es como reducir toda convivencia amorosa y matrimonial a un tipo de relación de pareja, que termina en los galpes, palizas e incluso en el asesinato de la mujer. Porque existan asesinatos algunas parejas asesinatos, no se puede globalmente afirmar que el matrimonio es la gangrena del amor y el camino del asesinato. Pues, mutatis mutandis, ese mensaje implícito es el que capta la opinión pública, con afirmaciones -académicamente tal vez correctas o al menos discutibles- de Giovanni Sartori que parecen reducir toda forma variada de multiculturalidad y multiculturalismo a una versión o tipo particular, unido al apartheid o a la getthoización, a la teocracia, a la dominación de la mujer, a la ablación del clítoris, etcétera. Ese singular "multiculturalismo" ninguno lo queremos, pero otro es posible y deseable (3).

3. Es oportuno citar la opinión de Manuel Pimentel, ex-Ministro de Trabajo con el PP y responsable de Migraciones en su periodo de Gobierno, en su articulo titulado, "Inmigración: algunas preguntas y respuestas" (EI Pais. 9-111-2002) "¿Es bueno o malo el multiculturalismo? La experiencia nos demuestra que el complejo concepto de multiculturalismo significa cosas distintas para personas distintas. Si por multiculturalismo entendemos que bajo una misma frontera convivan culturas distintas gobernadas por leyes propias y diferentes, no cabe duda que estariamos ante un fenómeno negativo y disgregador, que ocasionarla graves desequilibrios en el futuro. Es mejor el principio del Estado de Derecho: un pals, una ley. Si por multiculturalismo se entiende que cada persona pueda expresar su cultura. dentro del imperio de la ley del pals receptor. estartamos ante un hermoso ejercicio de libertad:" 
Nada mejor para terminar este ensayo y para mostrar la cara de un enriquecedor multiculturalismo, que la Declaración del Comité Español para el Año Europeo contra el Racismo, proclamada en Toledo (1997), que dice así:

"La riqueza en España y Europa, desde hace siglos, se nutre fundamentalmente de la diversidad de sus tradiciones, culturas, etnias, lenguas y religiones, y de la certeza de que los principios de tolerancia y convivencia democrática son la mejor garantía de la existencia de la propia sociedad española y europea, abierta y pluricultural: diversa.

España. por su tradición histórica de convivencia entre pueblos y culturas, por su pertenencia al Mediterráneo, así como sus lazos con lberoamérica, puede facilitar el establecimiento de modelos de relación multiétnicos y multiculturales. La realización de una sociedad democrática, social, plural y avanzada se fundamenta sobre el respeto de la dignidad igual de todos los seres humanos". 


\section{Bibliografía}

- ABAD, Luis V., CUCO. Alfonso e IZQUIERDO, Antonio. 1993 inmigración, pluralismo y tolerancia, Madrid, Editorial Popular.

- AMIN. Maalof, 1999, Identidades asesinas, Madrid. Alianza Editorial

- AZURMENDI, Mike, 2001, Estampas de El Ejido. Madrid, Taurus.

- ASEP/IMSERSO, 1998. Actitudes hacia los inmigrantes, Madrid, Colección Observatorio Permanente de la Inmigración. Instituto de Migraciones y Servicios Sociales.

- BASTIDE, Roger, 1980, El prójimo y el extraño. Buenos Aires, Amorrortu.

- CALVO BUEZAS, Tomás, 1981, Los más pobres en el país más rico: clase, raza y etnia en el movimiento campesino chicano. Madrid. Encuentros.

- CALVO BUEZAS. Tomás, 1990, Muchas

Américas: Cultura, Sociedad y politicas en América Latina, Madrid, Editorial Universidad Complutense.

- CALVO BUEZAS. Tomás, 1990, El racismo que viene: otros pueblos y culturas vistos por profesores $y$ alumnos, Madrid, Tecnos.

- CALVO BUEZAS, Tomás, 1990, ¿España racista?, Barcelona, Anthropos.

- CALVO BUEZAS, Tomás, 1993. El crimen racista de Aravaca. Crónica de una muerte anunciada, Madrid. Editorial Popular.

- CALVO BUEZAS. Tomás, 1995. Crece el racismo, también la solidaridad, Madrid, Tecnos.

- CALvo BUEZAS, Tomás. 1997, Racismoy solidaridad en jóvenes españoles, portugueses y latinoamericanos, Madrid, Libertarias.

- CALVO BUEZAS, Tomás, 1997, Valores en los jóvenes españoles, portugueses y latinoamericanos. Problemas y esperanzas de los protagonistas del siglo XXI. Madrid, Libertarias.

- CALVO BUEZAS. Tomás, 1998. La Patria Común Iberoamericana. Amores y desamores entre hermanos. Madrid, Libertarias.

- CALVO BUEZAS, Tomás, 2000, Inmigracióny Racismo. Asi sienten los jóvenes del siglo XXI, Madrid. Cauce Editorial.
- CALVO BUEZAS, Tomás, 2001. Inmigración y Universidad. Prejuicios racistas y valores solidarios, Madrid, Editorial Complutense.

- CALVO BUEZAS. Tomás. 2003. La escuela ante la inmigración y el racismo. Orientaciones de educación intercultural, Madrid, Editorial Popular.

- CALVO BUEZAS, Tomás, FERNÁNDEZ, R. y ROSON. A.G., 1993 Educar para la tolerancia, Madrid, Editorial Popular.

- CHECA, Francisco, (ed.)1998. Africanos en la otra orilla. Trabajo, cultura e integración en la España Mediterránea, Madrid. Editorial Icaria.

- COLECTIVO IOE, 1995. Discursos de los españoles sobre los extranjeros: Paradojas de la alteridad, Madrid, CIS.

- HUNTINGTON, Samuel P., 1997, El choque de civilizaciones y la reconfiguración del orden mundial, Barcelona. Piados.

- JORDAN. J.A., 1994. La escuela multicultural. Un reto para el profesorado. Barcelona. Editorial Paidós.

- KRISTEVA. Julia, 1991. Extranjeros para nosotros mismos, Barcelona, Plaza y Janés.

- LUCAS, Javier de, 1996, Puertas que se cierran: Europa como fortaleza, Barcelona, Icaria-Antrazyt.

- NAIR. Sami. 1997. Mediterráneo hoy. Entre el diálogo y el rechazo, Barcelona, Icaria-Antrazyt.

- PAJARES. Miguel, 1998. La inmigración en España: retos y propuestas, Barcelona, Icaria.

- SARTORI, Giovanni, 1998, La sociedad multiétnica, pluralismo, multicutturalismo y extranjeros, Madrid, Taurus.

- TODOROV. V. T., 1998. Cruce de culturas y mestijaze cultural, Bancelona.

W.AA.. 1995, 10 palabras clave sobre racismo $y$ xenofobia, Estella. EDV.

W.AA., 1997, El extranjero en la cultura europea de nuestros dias, Bilbao. Universidad de Deusto.

- WIEVIORKA, Michel, 1992, El espacio del racismo, Barcelona, Paídos. 